\title{
Repeated freeze-thaw cycles reduce the survival rate of osteocytes in bone-tendon constructs without affecting the mechanical properties of tendons
}

\author{
Kaori Suto $\cdot$ Ken Urabe $\cdot$ Kouji Naruse $\cdot$ Kentaro Uchida $\cdot$ \\ Terumasa Matsuura $\cdot$ Yuko Mikuni-Takagaki $\cdot$ Mitsutoshi Suto • \\ Noriko Nemoto $\cdot$ Kentaro Kamiya $\cdot$ Moritoshi Itoman
}

Received: 6 August 2010/Accepted: 18 November 2010/Published online: 30 November 2010

(C) The Author(s) 2010. This article is published with open access at Springerlink.com

\begin{abstract}
Frozen bone-patellar tendon bone allografts are useful in anterior cruciate ligament reconstruction as the freezing procedure kills tissue cells, thereby reducing immunogenicity of the grafts. However, a small portion of cells in human femoral heads treated by standard bone-bank freezing procedures survive, thus limiting the effectiveness of allografts. Here, we characterized the survival rates and mechanisms of cells isolated from rat bones and
\end{abstract}

K. Suto $\cdot$ K. Urabe $(\bowtie) \cdot$ K. Naruse $\cdot$ K. Uchida

T. Matsuura $\cdot$ M. Suto

Department of Orthopaedic Surgery, Kitasato University

School of Medicine, 1-15-1 Kitasato, Minami-ku,

Sagamihara, Kanagawa 252-0374, Japan

e-mail: kenurabe@med.kitasato-u.ac.jp

Y. Mikuni-Takagaki

Department of Science, Kanagawa Dental College, 82 Inaokacho, Yokosuka, Kanagawa 238-8580, Japan

N. Nemoto

Research Center for Biological Imaging, Kitasato University School of Medicine, 1-15-1 Kitasato, Minami-ku, Sagamihara, Kanagawa 252-0374, Japan

K. Kamiya

Rehabilitation Center, Kitasato University Hospital, 1-15-1 Kitasato, Minami-ku, Sagamihara, Kanagawa 252-0375, Japan

M. Itoman

Kyushu Rosai Hospital, 1-3-1 Kuzuhara-Takamatsu, Kokura-Minami, Kitakyushu, Fukuoka 800-0296, Japan tendons that were subjected to freeze-thaw treatments, and evaluated the influence of these treatments on the mechanical properties of tendons. After a single freeze-thaw cycle, most cells isolated from frozen bone appeared morphologically as osteocytes and expressed both osteoblast- and osteocyte-related genes. Transmission electron microscopic observation of frozen cells using freeze-substitution revealed that a small number of osteocytes maintained large nuclei with intact double membranes, indicating that these osteocytes in bone matrix were resistant to ice crystal formation. We found that tendon cells were completely killed by a single freeze-thaw cycle, whereas bone cells exhibited a relatively high survival rate, although survival was significantly reduced after three freeze-thaw cycles. In patella tendons, the ultimate stress, Young's modulus, and strain at failure showed no significant differences between untreated tendons and those subjected to five freeze-thaw cycles. In conclusion, we identified that cells surviving after freeze-thaw treatment of rat bones were predominantly osteocytes. We propose that repeated freeze-thaw cycles could be applied for processing bone-tendon constructs prior to grafting as the treatment did not affect the mechanical property of tendons and drastically reduced surviving osteocytes, thereby potentially decreasing allograft immunogenecity.

Keywords Allografts · Freeze-thawing · Bone-patellar tendon-bone $\cdot$ Osteocytes 


\section{Introduction}

Of the knee ligaments, the anterior cruciate ligament (ACL) is most prone to total disruption, which is often followed by repeated episodes of joint instability associated with meniscal injury, increased erosion of joint cartilage, and abnormal osseous metabolic activity (Beynnon et al. 2002). Conservative management of ACL deficiency leads to progressive rotatory instability, meniscal tears, and premature joint degeneration (Barrett 1991). To restore rotatory stability, reconstruction of the ACL is typically performed by a variety of grafting procedures using autografts, allografts, or artificial ligaments. Although autografts are nonimmunogenic and therefore represent a good alternative for the replacement of missing ligaments, allografts have many advantages over autografts, including a lack of donor site morbidity, shorter operation time, and larger grafts are possible (Kleipool et al. 1998). Despite these benefits, viable cells present in allografts are capable of eliciting host immune responses that reduce the effectiveness of ACL reconstruction, and it is unclear what cell types are responsible for the immunoreactivity.

Allografts are transplanted after they are subjected to various processes for reducing antigenicity, sterilization, and preservation. Freezing of tissues at $-80^{\circ} \mathrm{C}$ is generally used for long storage in tissue banks and is also considered to reduce immunogenicity of allografts as tissue cells are killed (Gitelis and Cole 2002; Weyts et al. 2003; Heyligers and Klein-Nulend 2005); however, recent studies have reported that a small portion of bone cells survive in human resected femoral heads after standard bonebank freezing protocols (Weyts et al. 2003; Heyligers and Klein-Nulend 2005; Simpson et al. 2007). As the detailed characterization of surviving cells in allografts has not been performed, it is important to identify surviving cell types and survival mechanisms during freezing procedures to more effectively target these cells and improve the success of allograft procedures.

During the freezing process, cells undergo injury due to intracellular ice crystal formation and the altered ionic concentrations of solutions (Gage and Baust 1998). Repeated freeze-thaw cycles result in greater tissue destruction than a single freeze-thaw cycle (Gill et al. 1968), due in large part to an increase in cell necrosis (Dilley et al. 1993). We therefore hypothesized that repeated freeze-thaw cycles would reduce the number of surviving cells in allografts, and potentially represents a simple method for reducing immunogenicity. Although we previously reported that a single freeze-thaw cycle did not affect the mechanical properties of tendons (Park et al. 2009), it is unclear how repeated freezethaw treatments would affect tendon mechanics and function.

The purpose of this study was to characterize the survival rate and mechanisms of cells from rat bones and tendons that were subjected to repeated freezethaw treatments, and evaluate the influence of these treatments on the mechanical properties of tendons.

\section{Materials and methods}

Bone preparation

Long bones (femora and tibiae) were harvested from 10-week-old male Wistar rats (Charles River Japan, Yokohama, Japan). Bones from 16 rats were divided into four freeze-thaw (FT) groups: (a) FT0, in which bones were fresh; (b) FT1, in which bones were frozen using an ultra-low temperature freezer (MDFU581, Sanyo Electric Co., Ltd, Osaka, Japan) and stored at $-80^{\circ} \mathrm{C}$ for 3 weeks; (c) FT2, in which FT1 were thawed at $37^{\circ} \mathrm{C}$ in for $1 \mathrm{~h}$, and then stored at $-80^{\circ} \mathrm{C}$ for 1 week; and (d) FT3, in which FT2 were subjected to a third thawing and freezing cycle and then stored at $-80^{\circ} \mathrm{C}$ for 1 week.

Isolation and culture of bone cells

For the isolation and culture of bone cells from the FT1 group, frozen bone samples were first thawed at room temperature in a phosphate-buffered saline without $\mathrm{Mg}^{2+}$ and $\mathrm{Ca}^{2+}(\operatorname{PBS}(-))$. Bone samples, including cartilage, were collected by chipping femora and tibiae with scissors. Pieces of bones were then digested twice with collagenase (Wako Pure Chemical Industries, Ltd., Osaka, Japan) in PBS containing $\mathrm{Mg}^{2+}$ and $\mathrm{Ca}^{2+}(\mathrm{PBS}(+))$ at $37^{\circ} \mathrm{C}$ on a rotary blood mixer for $15 \mathrm{~min}$, as previously described (Mikuni-Takagaki et al. 1995), and a single fraction (Fr) was collected after each digestion to yield Fr 1 and 2. Subsequently, pieces of bones were then consecutively digested three times with 
collagenase for $20 \mathrm{~min}$, and osteoblastic populations were obtained from each collagenase solution to give Fr 3, 4, and 5. After the collection of Fr 5, osteocyterich populations were obtained from the remaining cells by an initial incubation in $\mathrm{PBS}(-)$ containing 4 mM EDTA for 15 min to yield Fr 6-1, followed by a 15-min incubation in a collagenase solution for $15 \mathrm{~min}$ to give $\mathrm{Fr}$ 6-2. This procedure was repeated to yield Fr 7-1 and 7-2. Following the final digestion, cell suspensions were sequentially passed through 100 and $40 \mu \mathrm{m}$ filters and then cultured in type I collagen-coated culture dishes with alpha-minimum essential medium ( $\alpha$-MEM) supplemented with $5 \%$ fetal bovine serum (FBS), 5\% calf serum (CS), $0.25 \mathrm{mM}$ ascorbic acid, 100 units $/ \mathrm{ml}$ penicillin, and $100 \mu \mathrm{g} / \mathrm{ml}$ streptomycin for 1 week at $37^{\circ} \mathrm{C}$ in a humidified atmosphere containing $5 \% \mathrm{CO}_{2}$ (MCO20AIC, Sanyo Electric Co., Ltd., Osaka, Japan). Adherent bone cells were then observed by phasecontrast microscopy (ECLIPSE TS100, Nikon, Tokyo, Japan) and cell survival frequency (frequency of at least one cell surviving) was then calculated.

Isolation and culture of tendon cells

Patellar tendons (PTs) were collected from both knees of 15 10-week-old male Wistar rats after being freed from surrounding tissues using sharp scissors. The harvested PTs were divided into an FT0 group, which consisted of fresh PTs, and an FT1 group, which consisted of PTs that were frozen using an ultra-low temperature freezer, stored at $-80^{\circ} \mathrm{C}$ for 3 weeks, and then thawed at room temperature in PBS(-). Tendon cells were harvested by collagenase digestion, as previously described (Scutt et al. 2008). Briefly, PTs were rinsed once in $\operatorname{PBS}(-)$, diced into small pieces, and then digested in a sterile collagenase solution for either 4,8 , or $18 \mathrm{~h}$ at $37^{\circ} \mathrm{C}$ on a rotary blood mixer at $180 \mathrm{rpm}$. Following digestion, cell suspensions were sequentially passed through 100 and $40 \mu \mathrm{m}$ filters, and then cultured in culture dishes with Dulbecco's Modified Eagle Medium (D-MEM) containing 10\% FBS, $50 \mu \mathrm{g} / \mathrm{ml}$ ascorbic acid, $100 \mathrm{units} / \mathrm{ml}$ penicillin, and $100 \mu \mathrm{g} / \mathrm{ml}$ streptomycin. After 1 week, PT-derived adherent cells were observed by phase-contrast microscopy and cell survival rate was calculated.

Reverse transcription-polymerase chain reaction (RT-PCR)

To determine the characteristics of surviving cells, cell marker gene expression was analyzed by RTPCR. Total cellular RNA was first extracted with Trizol Reagent (Invitrogen, Carlsbad, USA) according to the manufacturer's instructions. To generate cDNA from total RNA, reverse transcription was performed using SuperScript ${ }^{\mathrm{TM}}$ II Reverse Transcriptase (Invitrogen, Carlsbad, USA) (Naruse et al. 2000; Uchida et al. 2007). Expression of the osteoblast-related marker genes alkaline phosphatase (ALP), parathyroid hormone receptor (PTHr), alpha-1 type I collagen (COL1A1), and osteocalcin (OCN) and the osteocyte-related marker genes sclerostin (SOST) and dentin matrix protein-1 (DMP-1) in Fr 5-7 was analyzed by RT-PCR. Newly designed primers were used to amplify OCN, SOST, and DMP-1 (Table 1), and primers designed based on previously published cDNA sequences (Naruse et al. 2004; Uchida et al. 2007) were used for all other target genes. All primers were purchased from Sigma Genosys (Hokkaido, Japan).

Table 1 Primer pairs used for PCR amplification

\begin{tabular}{|c|c|c|c|c|}
\hline Target gene & Accession no. ${ }^{a}$ & Primer pair sequences (sense/antisense) ${ }^{\mathrm{b}}$ & Base pairs & Cycles \\
\hline OCN & X04141 & $\begin{array}{l}\text { 5'-TGAGGACCCTCTCTCTGCTC-3' } \\
5^{\prime} \text {-ACCTTACTGCCСТCСТGCTT-3' }\end{array}$ & 127 & 30 \\
\hline SOST & AF326741 & $\begin{array}{l}\text { 5'-CAGCTCTCACTAGCCCCTTG-3' } \\
\text { 5'-CTCGGACACGTCTTTGGTGT-3' }^{\prime}\end{array}$ & 228 & 30 \\
\hline DMP-1 & NM_203493 & $\begin{array}{l}\text { 5'-AGTTCGATGATGAGGGGATG-3' } \\
\text { 5'-AGTCTCGCTCCTGCTTTCCT-3 }^{\prime}\end{array}$ & 299 & 30 \\
\hline
\end{tabular}

OCN Osteocalcin, SOST sclerostin, DMP-1 dentin matrix protein-1

${ }^{a}$ Genbank accession number of the sequences used in designing the primers

b Primer sequences were designed using BLUEPHIN software (Sigma Genosys, Japan) 
RT-PCR was performed under linear conditions, and the following conditions were used for the amplification of all genes: an initial denaturation for $5 \mathrm{~min}$ at $94^{\circ} \mathrm{C}$, followed by a cycle of denaturation at $94^{\circ} \mathrm{C}$ for $30 \mathrm{~s}$, a specific annealing temperature $\left(55-60^{\circ} \mathrm{C}\right)$ for each pair of primers for $30 \mathrm{~s}$, extension at $72^{\circ} \mathrm{C}$ for $30 \mathrm{~s}$, followed by a final elongation step of $2 \mathrm{~min}$ at $72^{\circ} \mathrm{C}$. Amplified PCR products were separated on a $3 \%$ agarose gel and stained with ethidium bromide for visualization.

Histological analysis

The cells from fresh and frozen bone were also examined by transmission electron microscopy (TEM). Fresh specimens were pre-fixed with $0.1 \mathrm{M}$ cacodylate buffer containing $4 \%$ paraformaldehyde and $2.5 \%$ glutaraldehyde, and then post-fixed with $2 \%$ osmium tetraoxide in $0.1 \mathrm{M}$ cacodylate buffer and embedded in Quetol 651 resin (Nissin EM Corp., Tokyo, Japan) according to the manufacturer's instructions. In addition, to evaluate the structure of bone cells in the frozen state, bones were fixed using a freeze-substitution method, as previously described (Park et al. 2009). Briefly, bones were first transferred to acetone containing $2 \%$ osmium tetroxide $\left(\mathrm{OsO}_{4}\right)$ cooled at $-80^{\circ} \mathrm{C}$, and then stored at $-80^{\circ} \mathrm{C}$ for 1 week. For freeze-substitution, the temperature was elevated stepwise from $-20^{\circ} \mathrm{C}$ for 3 days to $4^{\circ} \mathrm{C}$ for 3 days. The bones were then added to acetone and washed once with cacodylate buffer at room temperature and embedded in Quetol 651 resin. Cross and longitudinal sections were prepared using an Ultracut UCT ultramicrotome (Leica, Deutsch), stained with $3.5 \%$ uranyl acetate and lead citrate, and examined with a transmission electron microscope (Hitachi H-8100; Hitachi, Hitachinaka, Japan).

\section{Mechanical testing of tendons}

Bone-patellar tendon-bones (BTBs) from both knees of 24 rats were harvested and divided into three groups: (a) FT0, in which BTBs were fresh; (b) FT1, in which BTBs were frozen using an ultra-low temperature freezer and stored at $-80^{\circ} \mathrm{C}$ for 3 weeks; and (c) FT5, in which BTBs were repeatedly frozen and thawed five times. Immediately prior to testing, all BTBs were allowed to thaw at room temperature in PBS for $3 \mathrm{~h}$. For mechanical testing, we analyzed eight BTB specimens in each group as previously described (Park et al. 2009). Briefly, tendons of BTBs from each group were trimmed to $1 \mathrm{~mm}$ in width and their free length was measured using a micrometer caliper. The cross-sectional areas of the tendons were calculated by measuring the width and thickness. The BTB specimens were then mounted using a 27-gauge injection needle in a specially designed device containing resin (OSTRON II; GC Dental Products Corp., Aichi, Japan) to maintain $30^{\circ}$ of flexion to the patellar tendon in the sagittal plane and to fix the axis of loading to match that of the patellar tendon. The specimens were tested to failure on a universal testing machine at a strain rate of $9 \mathrm{~mm} / \mathrm{min}$, with force detected using a load cell (Showa Measuring Instruments Inc., Tokyo, Japan) with a maximum capacity of $50 \mathrm{~N}$ to obtain load deformation curves. Stressstrain curves were then calculated from the loaddeformation curves. The mode of failure was noted as a break at the mid-substance of the tendon, because nearly all rat patellar tendons were broken at midsubstance under our experimental conditions, regardless of the number of freeze-thaw cycles, strain rate, and temperature. Ultimate stress, Young's modulus, and strain at failure were obtained from the stressstrain curves. Ultimate stress was defined as the peak force of the stress-strain curves, while Young's modulus was calculated using the most linear portion of the failure curve.

Statistical analysis

A multiple comparison test based on Ryan's method was used to evaluate significant differences among survival rates of the three groups. The significance level was set at 0.008 in this study. To compare the mechanical properties of the tendons between the three groups, statistical assessment was performed using one-way analysis of variance (ANOVA) with Tukey's multiple test. A $P$ value of $<0.05$ was considered statistically significant.

\section{Results}

Cell morphology of cells isolated from bone

After the isolation of bone cells from femora and tibiae of 10-week-old male Wistar rats, we examined 

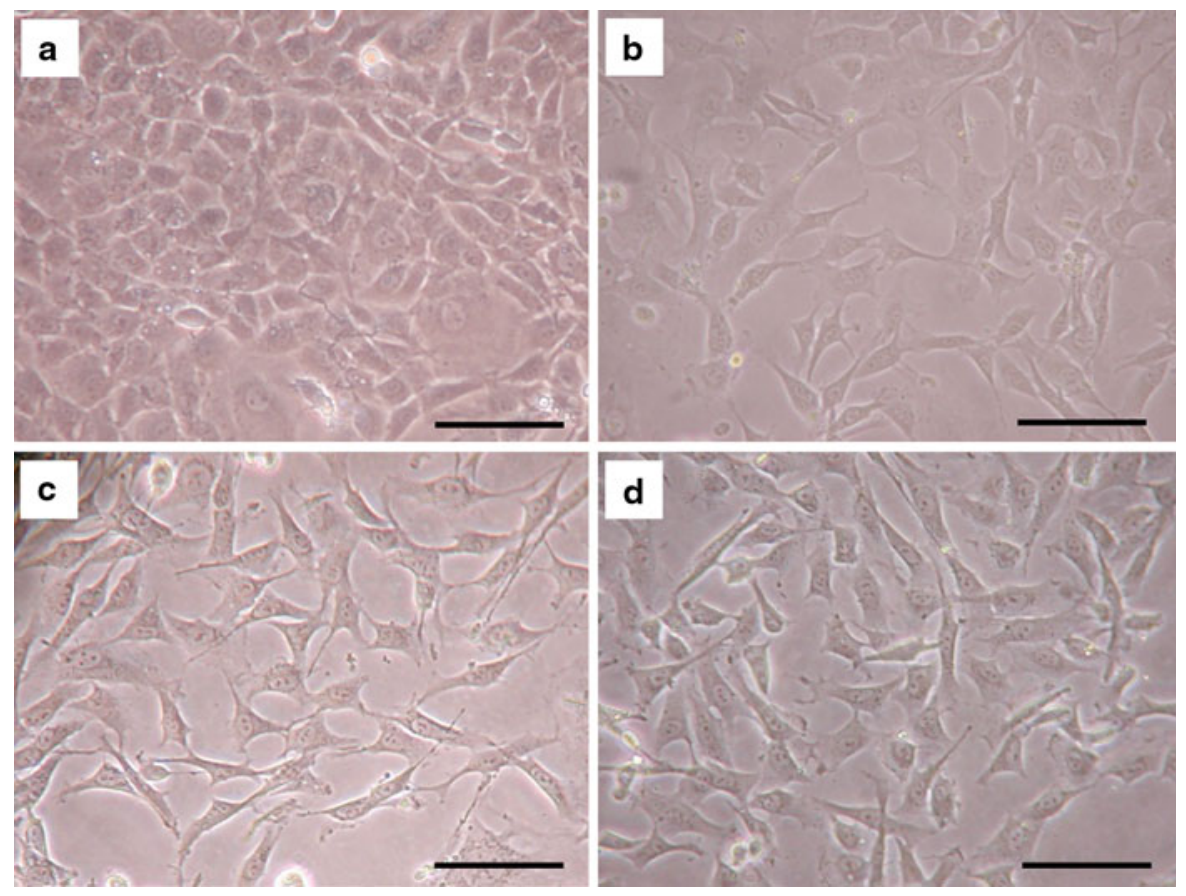

Fig. 1 Cell morphology of cells isolated from rat femoral and tibial bones. Phase-contrast microscopic images of isolated bone cells from two freeze-thaw (FT) treatment groups.

adherent cells to type I collagen-coated culture dishes by phase-contrast microscopy (Fig. 1). The cells in Fr 5,6 , and 7 that were isolated from bone samples without freeze-thaw treatment (FT0) showed two types of morphologies. Approximately half of the cells displayed an osteoblastic morphology and appeared spherical to slightly flattened, which when assembled, appeared cuboidal and displayed a cobble-stone pattern (Fig. 1a). The other type of adherent cells showed osteocytic morphology with a high cytoplasmto-nucleus ratio, and developed extensive radial cell processes and contacted adjacent cells (Fig. 1b). In Fr 5,6 , and 7 , which were obtained from cell suspensions subjected to either one or two freeze-thaw cycles (FT1 and 2, respectively), nearly all cells had a similar morphology to the osteocytic cell type in Fr 5, 6, and 7 isolated from FT0 (Fig. 1c, d).

Expression of osteoblast- and osteocyte-related marker genes

To further characterize the isolated adherent bone cells, the expression of cell-marker genes was analyzed by RT-PCR. The bone cells in Fr 5, 6 , a Osteoblastic cells in FT0, b osteocytic cells in FT0, c osteocytic cells in FT1. d Osteocytic cells in FT3. The scale bars indicate $100 \mu \mathrm{m}$

and 7 isolated from FT0 expressed several osteoblast-related marker genes, including ALP, PTHr, COL1A1, and OCN (Fig. 2). These cells also expressed the osteocyte-related gene SOST. The expression of DMP-1 was detected in Fr 5 isolated from FT0. The cells in Fr 5, 6, and 7 isolated from FT1 expressed ALP, PTHr, COL1A1, and DMP-1, but the expression of OCN and SOST was not detected. Our preliminary data showed that expression of OCN and SOST increased in a cell densitydependent manner, whereas higher expression levels of DMP-1 were observed at lower cell densities (data not shown).

\section{TEM of bone cells}

In an attempt to reveal the survival mechanisms of cells in frozen bone tissue, we next observed the cell morphology of isolated osteoblasts and osteocytes in fresh and frozen states using TEM (Fig. 3). In a fresh state, osteoblasts were flattened along bone surfaces and nuclei located at the distal end of cells could be observed (Fig. 3a). In addition, their cytoplasm contained abundant rough endoplasmic reticulum and numerous free 


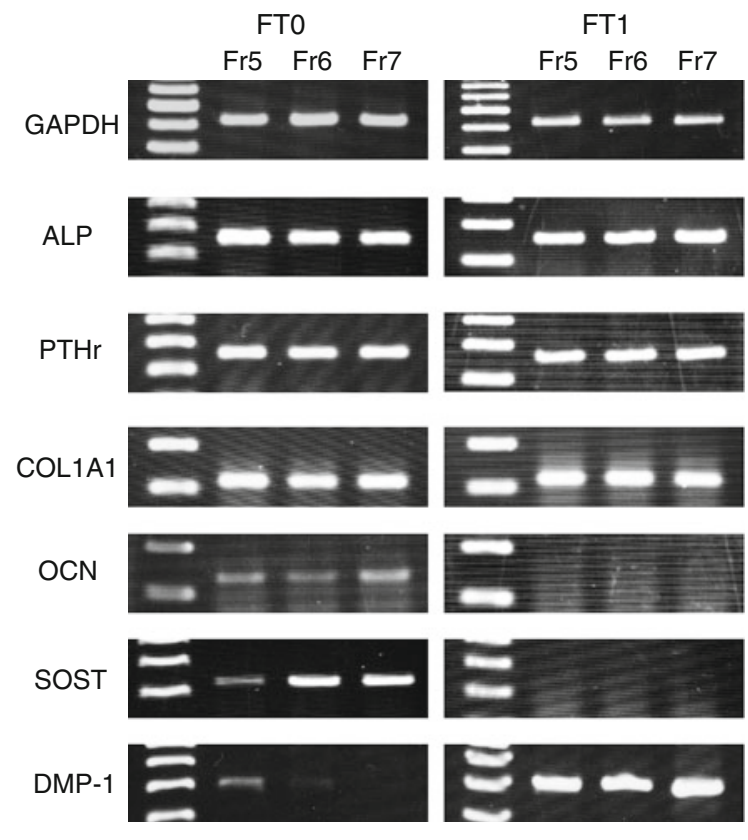

Fig. 2 Expression of osteoblast- and osteocyte-related marker genes. RT-PCR was used to analyze the expression of the indicated cell-marker genes in bone cells isolated in fraction (Fr) 5-7 from the freeze-thaw (FT) groups FT0 and FT1. GAPDH, glyceraldehydes-3-phosphate dehydrogenase; $A L P$ alkaline phosphatase, $\mathrm{PTHr}$ parathyroid hormone receptor, COL1 alpha-1 type I collagen, OCN osteocalcin, SOST sclerostin, and $D M P-1$ dentin matrix protein 1

ribosomes and mitochondria were also detected. After subjecting osteoblasts to freeze-substitution, nearly all frozen cells were shrunk and contained condensed chromatin granules densely arranged around the inner rim of the nuclear membrane (Fig. 3b). In these cells, the nuclear envelope and cytoplasmic membrane appeared broken down and disrupted.

In contrast to osteoblasts, freshly isolated osteocytes appeared more rounded with relatively large nuclei (Fig. 3c). Cell organelles, such as lysosomes and rough endoplasmic reticulum were clearly observed. In the frozen state, numerous shrunken osteocytes contained condensed chromatin granules that were arranged densely at the inner rim of the nuclear membrane, similar to osteoblasts, but the distribution was more sparse and typically located in the center of the nucleus (Fig. 3d). In addition, a number of frozen cells had nuclear envelopes that were disrupted and clearly destroyed. However, several cells maintained relatively large nuclei without cytoplasmic shrinkage, and double layers of nuclear membrane without any interruption were also observed.
Effect of freeze-thaw cycle number on cell survival rate in bone and tendons

Following the isolation and culture of cells from rat femora and tibiae, it was confirmed that surviving cells were present in all fractions from each of the eight bone samples in the FT0 group (8/8) (Table 2). Upon a single freeze-thaw treatment, however, the cell survival rate in Fr 1 from FT1 (2/8) was significantly lower compared with Fr 1 from FT0 $(8 / 8)(P<0.008)$. An additional cycle of freezethawing further reduced the cell survival rate, with no viable cells observed in Fr $1(0 / 8)$ and only limited survival in Fr $2(2 / 8)$ from FT2 $(P<0.008)$. The cell survival rate in Fr 3 to 7 from FT2 also decreased, however, the differences were not statistically significant from Fr 3 to 7 of the FT0 group. Subjecting the isolated bone cells to a third round of freeze-thawing drastically reduced the cell survival rate, as all fractions from FT3 showed significantly decreased survival compared with FT0 $(P<0.008)$ and no detectable surviving cells in the first three fractions (Fr 1-3; 0/0).

Finally, the survival of cells harvested from tendons in the FT0 and FT1 were compared after variable incubation times after freeze-thaw treatment (Table 3). Similar to the isolated bone cells, while tendon-derived adherent cells were observed in all samples of the FT0 group, no adherent cells in the FT1 group were detected after 4-, 8-, or 18-h incubation periods (Table 3).

Mechanical properties of tendons

To compare the effects of freeze-thawing on the mechanical properties of tendons, BTB samples from the three freeze-thaw treatment groups were assayed by the tensile failure test (Table 4). Tendon failure in all BTB samples occurred at the mid-substance under our experimental conditions. The ultimate stress, Young's modulus profiles, and strain at failure showed no significant differences among the FT0, FT1, and FT5 groups.

\section{Discussion}

We examined the survival rate of cells isolated from rat bones and tendons that were subjected to freeze- 

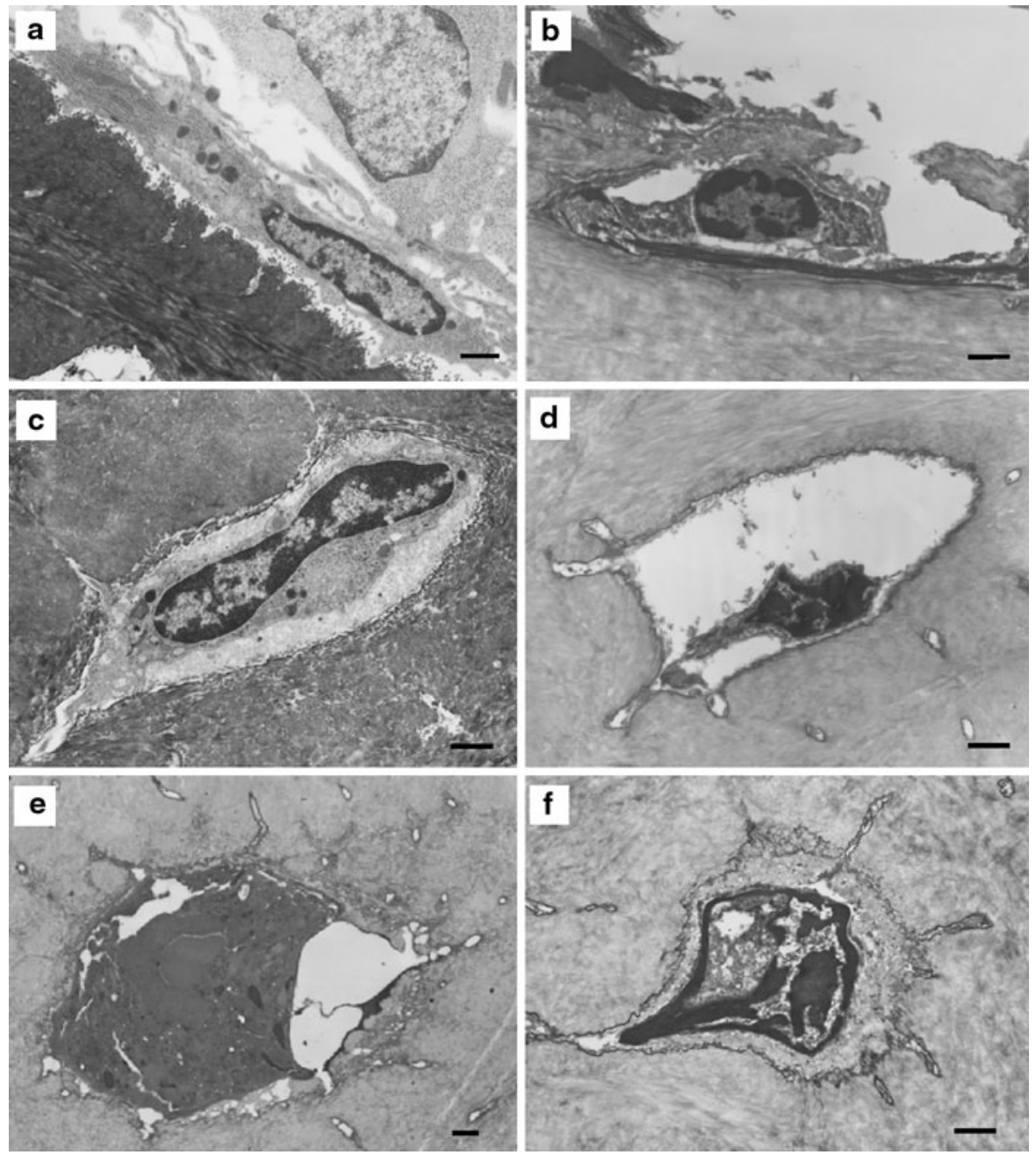

Fig. 3 Transmission electron microscopic images of bone cells in fresh and frozen states. a Osteoblastic cell in a fresh

fresh state. $\mathbf{d}-\mathbf{f}$ Osteocytic cells in a frozen state. The scale bars indicates $1 \mu \mathrm{m}$

thaw treatment. Results showed that tendon cells were completely killed by a single freeze-thaw cycle, whereas bone cells exhibited a relatively high survival rate, although the cell survival rate was significantly reduced after three freeze-thaw cycles. Nearly all cells isolated from femora and tibiae after a single freeze-thaw cycle appeared morphologically as osteocytes and expressed both osteoblast- and osteocyte-related genes. TEM images of freezesubstituted bone revealed that a number of osteocytes maintained large intact nuclei and cytoplasm, indicating that a portion of osteocytes in bone matrix were resistant to ice crystal formation. In addition, although tendon cells were completely killed after

freezing, five consecutive freeze-thaw cycles did not affect the mechanical properties of tendons.

Previous studies have shown that freshly frozen human femoral head allografts contain viable cells upon thawing that are morphologically indistinguishable from those cultured from freshly harvested trabecular bone, and display similar mRNA profiles with respect to osteoblast-related gene expression (Simpson et al. 2007). In our present investigation involving femoral and tibial bones from Wistar rats, surviving cells could be cultured from freshly frozen bone. Nearly all of the isolated cells were morphologically characterized as osteocytes and were indistinguishable from fresh bone-derived osteocytic cells. 
Table 2 Effect of freeze-thaw cycle number on cell survival rate in bone

\begin{tabular}{llllllll}
\hline & Fr 1 & Fr 2 & Fr 3 & Fr 4 & Fr 5 & Fr 6 & Fr 7 \\
\hline FT0 & $8 / 8$ & $8 / 8$ & $8 / 8$ & $8 / 8$ & $8 / 8$ & $8 / 8$ & $8 / 8$ \\
FT1 & $2 / 8^{*}$ & $8 / 8$ & $8 / 8$ & $8 / 8$ & $8 / 8$ & $8 / 8$ & $8 / 8$ \\
FT2 & $0 / 8^{*}$ & $2 / 8^{*}$ & $3 / 8$ & $3 / 8$ & $3 / 8$ & $4 / 8$ & $3 / 8$ \\
FT3 & $0 / 8^{*}$ & $0 / 8^{*}$ & $0 / 8^{*}$ & $1 / 8^{*}$ & $1 / 8^{*}$ & $2 / 8^{*}$ & $2 / 8^{*}$ \\
\hline
\end{tabular}

$F T$ Freeze-thaw, $F r$ fraction

* Nominal significance level for FT0 $(P<0.008)$

Table 3 Effect of a single freeze-thaw cycle on cell survival rate in tendons

\begin{tabular}{llll}
\hline Group & \multicolumn{2}{l}{ Incubation time (h) } \\
\cline { 2 - 4 } & 4 & 8 & 18 \\
\hline FT0 & $5 / 5$ & $5 / 5$ & $5 / 5$ \\
FT1 & 0 & 0 & 0 \\
\hline
\end{tabular}

FT Freeze-thaw

Although the cells isolated from frozen bone expressed both osteoblast- and osteocyte-related genes, the expression of OCN, DMP-1, and SOST was only observed in cells isolated from untreated bone samples. Expression profiles of OCN, DMP-1 and SOST may be affected by cell density rather than cell phenotype, because cell survival rates decrease with freeze-thawing treatment. Our results suggest that not only osteoblasts, but also osteocytes, survive in freeze-thawed bone.

Moreover, we also examined cell morphology in the frozen state to reveal the survival mechanisms of cells in frozen bone tissue. TEM images of bone cells subjected to a freeze-substitution method revealed that subcellular organelles in many cells were destroyed by ice crystals (Fig. 3). Surprisingly, a small percentage of osteocytes maintained relatively large nuclei with double-layered membranes and intact cell membranes and cytoplasm. Suspended and adherent cells were nearly completely killed by freeze-thawing in the absence of cryoprotectant (Shimada 1977). We speculate that the bone microenvironment, particularly the bone matrix which surrounds osteocytes provides protection from cryoinjury, such as the damage caused by ice crystal formation and salt injury. The importance of the bone matrix for protection is also supported by the fact that no cells survived in tendons after freezing, and indicates the matrix plays a role in the survival mechanism of osteocytes, which were the predominant cells isolated after the freeze-thaw treatment of bone.

Several studies have reported that surviving cells in allograft tissue are potentially immunogenic (Enneking 1957; Chalmers 1959; Langer et al. 1975). For example, Rodeo et al. (2000) reported that class-I and -II major histocompatibility complex antigens persist on cells of a meniscus prepared for transplantation even after two freeze-thaw cycles. It is therefore considered that the complete killing of cells is important for successful allogenic transplantations. Compared to a single freeze-thaw treatment, the repeated freeze-thaw of tissues, including the palate, liver, and skin, is known to produce more extensive and thorough tissue destruction and increase necrosis (Gage and Baust 1998). Here, we found that tendon cells were completely killed by a single freeze-thaw cycle, while bone cells were significantly reduced after three freeze-thaw cycles. Cryobiological research has demonstrated that all parts of the freeze-thaw cycle, particularly the cooling and warming rates, are associated with tissue destruction and cell injury (Gage and Baust 1998). For example, intracellular ice crystal formation is more likely to occur with rapid cooling rates (Gage and Baust 1998). As we have demonstrated that osteocytes survive even after three consecutive freeze-thaw cycles, further investigation is needed to reveal the conditions required for complete disappearance of allograft immunogenicity using freeze-thaw cycles.
Table 4 Mechanical properties of tendons subjected to freeze-thaw treatment

FT freeze thaw

All values are presented as the mean $\pm \mathrm{SD}$

\begin{tabular}{lllll}
\hline Group & $\begin{array}{l}\text { Number of } \\
\text { samples }\end{array}$ & $\begin{array}{l}\text { Ultimate } \\
\text { stress }(\mathrm{MPa})\end{array}$ & $\begin{array}{l}\text { Young's modulus } \\
(\mathrm{MPa})\end{array}$ & $\begin{array}{l}\text { Strain at } \\
\text { failure (\%) }\end{array}$ \\
\hline FT0 & 8 & $42.6 \pm 16.3$ & $206.8 \pm 99.2$ & $22.0 \pm 4.8$ \\
FT1 & 8 & $30.7 \pm 17.8$ & $185.0 \pm 119.4$ & $17.4 \pm 4.1$ \\
FT5 & 8 & $46.1 \pm 17.9$ & $211.4 \pm 108.3$ & $23.8 \pm 4.9$ \\
\hline
\end{tabular}


The initial strength of tendons used for transplantation is important for successful ACL reconstruction. Several studies have reported that the various procedures used for tendon allograft preparation, such as freezing and irradiation, adversely affect the mechanical properties of tendons (Clavert et al. 2001; Fideler et al. 1995; Noyes and Grood 1976). Conflicting results regarding the effects of cryopreservation on the mechanical properties of tendons have been reported, with several studies stating that mechanical properties are not affected (Nikolaou et al.1986; Noyes and Grood 1976; Woo et al. 1986), while others have indicated that biomechanical changes did occur (Clavert et al. 2001; Smith et al. 1996). Although we previously found that the mechanical properties of rat tendons subjected to a single freezethaw cycle were not significantly different than those of fresh tendons (Park et al. 2009). In the present study, even an additional four freeze-thaw cycles did not significantly decrease the mechanical properties of rat tendons. Our previous study showed that many spaces were present in the interfibrillar substance of tendons, and collagen fibrils were divided and squeezed by these spaces in the frozen state. However, such spaces and ice crystal formation were not observed in freeze-thawed tendons (Park et al. 2009). In addition, we did not observe significant differences in the fibril occupation ratio and cycle length of intraperiodic bands of collagen fibrils between the control and freeze-thawed tendons. Taken together, these results suggest that repeated freeze-thaw cycles may not significantly affect the mechanical properties of tendons.

A number of studies using animal models, including dogs, monkeys, and rats, have shown that mechanical of tendons failure mostly occurs at tibial insertion sites during tensile testing (Clavert et al. 2001; Noyes and Grood 1976; Shino et al. 1984; $\mathrm{Su}$ et al. 2008). Our preliminary experiments also revealed that nearly all BTBs failed at tibial insertion sites when the tibial tuberosity was maintained at $0^{\circ}$ of flexion to the patellar tendon in the sagittal plane (data not shown). We previously attempted to optimize experimental conditions to evaluate the mechanical properties of tendon substances and found that failure of tendons reproducibly occurred at mid-substance with when the tibial tuberosity was held at $30^{\circ}$ of flexion to the patellar tendon in the sagittal plane. Here, we therefore evaluated the effects of repeated freeze-thaw cycles on tendon substances under these previous experimental conditions. In clinical situations, cruciate ligament ruptures occur not only in mid-substance, but also at insertion sites. Thus, further investigation under other experimental conditions may be needed to confirm the applicability of our current findings to clinical situations.

In conclusion, we found that surviving cells in rat femoral and tibial bones subjected to freeze-thawing consisted of not only osteoblasts, but also significant numbers of osteocytes. We demonstrated that tendon cells were completely killed by a single freeze-thaw cycle, while bone cells displayed relatively high survival rates, although survival was significantly reduced after three freeze-thaw cycles. Significantly, five consecutive freeze-thaw cycles did not affect the mechanical properties of rat tendons in this experiment.

Acknowledgments This investigation was supported in part by grants-in-aid from the Ministry of Education, Sports, Culture, Science, and Technology of Japan and by grants-inaid from the Ministry of Health, Labour, and Welfare, Japan for Research on Human Genome, Tissue Engineering, and Food Biotechnology to M. I.. This research was also supported by grants-in-aid from the Ministry of Education, Sports, Culture, Science, and Technology of Japan to K. N. and K. U., and by research grants from the Parents' Association of Kitasato University School of Medicine, the Nakatomi Foundation, and SDS Inc. to K. N.

Open Access This article is distributed under the terms of the Creative Commons Attribution Noncommercial License which permits any noncommercial use, distribution, and reproduction in any medium, provided the original author(s) and source are credited.

\section{References}

Barrett DS (1991) Proprioception and function after anterior cruciate reconstruction. J Bone Joint Surg Br 73:833-837

Beynnon BD, Johnson RJ, Fleming BC, Kannus P, Kaplan M, Samani J, Renstrom P (2002) Anterior cruciate ligament replacement comparisn of bone-patellar tendon-bone grafts with two-strand hamstring grafts. A prospective, randomized study. J Bone Joint Surg Am 84A:1503-1513. doi:10.1007/s00421-008-0955-8

Chalmers J (1959) Transplantation immunity in bone homografting. J Bone Joint Surg Br 41-B:160-179

Clavert P, Kempf JF, Bonnomet F, Boutemy P, Marcelin L, Kahn JL (2001) Effects of freezing/thawing on the 
biomechanical properties of human tendons. Surg Radiol Anat 23:259-262. doi:10.1007/s00276-001-0259-8

Dilley AV, Dy DY, Warlters A, Copeland S, Gillies AE, Morris RW, Gibb DB, Cook TA, Morris DL (1993) Laboratory and animal model evaluation of the Cryotech LCS 2000 in hepatic cryotherapy. Cryobiology 30:74-85. doi:10.1006/cryo.1993.1007

Enneking WF (1957) Histological investigation of bone transplants in immunologically prepared animals. J Bone Joint Surg Am 39-A:597-615

Fideler BM, Vangsness CT Jr, Lu B, Orlando C, Moore T (1995) Gamma irradiation: effects on biomechanical properties of human bone-patellar tendon-bone allografts. Am J Sports Med 23:643-646. doi:10.1177/036354659502300521

Gage AA, Baust J (1998) Mechanisms of tissue injury in cryosurgery. Cryobiology 37:171-186. doi:10.1006/cryo. 1998.2115

Gill W, Fraser J, Carter DC (1968) Repeated freeze-thaw cycles in cryosurgery. Nature 219:410-413. doi:10.1038/ 219410a0

Gitelis S, Cole BJ (2002) The use of allografts in orthopaedic surgery. Instr Course Lect 51:507-520

Heyligers IC, Klein-Nulend J (2005) Detection of living cells in non-processed but deep-frozen bone allografts. Cell Tissue Bank 6:25-31. doi:10.1007/s10561-005-1089-4

Kleipool AE, Zijl JA, Willems WJ (1998) Arthroscopic anterior cruciate ligament reconstruction with bone-patellar tendonbone allograft or autograft. A prospective study with an average follow up of 4 years. Knee Surg Sports Traumatol Arthrosc 6:224-230. doi:10.1007/s001670050104

Langer F, Czitrom A, Pritzker KP, Gross AE (1975) The immunogenicity of fresh and frozen allogeneic bone. J Bone Joint Surg Am 57:216-220

Mikuni-Takagaki Y, Kakai Y, Satoyoshi M, Kawano E, Suzuki Y, Kawase T, Saito S (1995) Matrix mineralization and the differentiation of osteocyte-like cells in culture. J Bone Miner Res 10:231-242. doi:10.1002/jbmr.5650100209

Naruse K, Mikuni-Takagaki Y, Azuma Y, Ito M, Oota T, Kameyama K, Itoman M (2000) Anabolic response of mouse bone-marrow-derived stromal cell clone ST2 cells to low-intensity pulsed ultrasound. Biochem Biophys Res Commun 268:216-220. doi:10.1006/bbrc.2000.2094

Naruse K, Urabe K, Mukaida T, Ueno T, Migishima F, Oikawa A, Mikuni-Takagaki Y, Itoman M (2004) Spontaneous differentiation of mesenchymal stem cells obtained from fetal rat circulation. Bone 35:850-858. doi:10.1016/ j.bone.2004.05.006

Nikolaou PK, Seaber AV, Glisson RR, Ribbeck BM, Bassett FH III (1986) Anterior cruciate ligament allograft transplantation. Long-term function, histology, revascularization, and operative technique. Am J Sports Med 14:348-360. doi:10.1177/036354658601400502

Noyes FR, Grood ES (1976) The strength of the anterior cruciate ligament in humans and Rhesus monkeys. J Bone Joint Surg Am 58:1074-1082

Park HJ, Urabe K, Naruse K, Onuma K, Nemoto N, Itoman M (2009) The effect of cryopreservation or heating on the mechanical properties and histomorphology of rat bonepatellar tendon-bone. Cell Tissue Bank 10:11-18. doi:10.1007/s10561-008-9109-9

Rodeo SA, Seneviratne A, Suzuki K, Felker K, Wickiewicz TL, Warren RF (2000) Histological analysis of human meniscal allografts. A preliminary report. J Bone Joint Surg Am 82-A:1071-1082

Scutt N, Rolf CG, Scutt A (2008) Tissue specific characteristics of cells isolated from human and rat tendons and ligaments. J Orthop Surg Res 3:32. doi:10.1186/1749-799X3-32

Shimada K (1977) Effect of cryoprotective addictives on intracellular ice formation and survival in very rapidly cooled Hela cells. Contrib Inst Low Temp Sci 19:49-70

Shino K, Kawasaki T, Hirose H, Gotoh I, Inoue M, Ono K (1984) Replacement of the anterior cruciate ligament by an allogeneic tendon graft. An experimental study in the dog. J Bone Joint Surg Br 66:672-681

Simpson D, Kakarala G, Hampson K, Steele N, Ashton B (2007) Viable cells survive in fresh frozen human bone allografts. Acta Orthop 78:26-30. doi:10.1080/ 17453670610013385

Smith CW, Young IS, Kearney JN (1996) Mechanical properties of tendons: changes with sterilization and preservation. J Biomech Eng 118:56-61

Su WR, Chen HH, Luo ZP (2008) Effect of cyclic stretching on the tensile properties of patellar tendon and medial collateral ligament in rat. Clin Biomech (Bristol., Avon.) 23: 911-917

Uchida K, Urabe K, Naruse K, Ujihira M, Mabuchi K, Itoman M (2007) Comparison of the cytokine-induced migratory response between primary and subcultured populations of rat mesenchymal bone marrow cells. J Orthop Sci 12:484-492. doi:10.1007/s00776-007-1159-5

Weyts FA, Bos PK, Dinjens WN, van Doorn WJ, van Biezen FC, Weinans H, Verhaar JA (2003) Living cells in 1 of 2 frozen femoral heads. Acta Orthop Scand 74:661-664. doi:10.1080/00016470310018162

Woo SL, Orlando CA, Camp JF, Akeson WH (1986) Effects of postmortem storage by freezing on ligament tensile behavior. J Biomech 19:399-404 